\title{
Patrimonio, democracia y sociedad
}

Fernando Carrera Ramírez | Escola Superior de Conservación e Restauración de Bens Culturais de Galicia, presidente de la Asociación de Conservadores Restauradores de España

URL de la contribución <www.iaph.es/revistaph/index.php/revistaph/article/view/3858>

Como técnicos que vivimos con el patrimonio cultural (pero también de él), tenemos la profunda impresión de habernos perdido en una mirada tozuda hacia nuestro persistentemente oculto- ombligo. Quizá nos hayamos enzarzado en debates sobre significados y límites conceptuales, pero también en otros sobre distribución de competencias, criterios de intervención o soluciones técnicas. Puro vacío para una sociedad a la que todo esto le importaba muy poco, como demostró el conocido caso del Ecce Homo ${ }^{1}$.

Mientras tanto, la materialidad del patrimonio se degradaba y el componente intangible desaparecía en el vértigo de lo contemporáneo. Y nada, desde la llegada de la democracia a España, parece que hayamos sido capaces de hacer para frenar esa sangría. Los pequeños brillos, aquí y allá, no han sido iniciativas coordinadas y apenas han superado el ámbito académico o administrativo.

Todo debate teórico es legítimo, saludable y provechoso, mientras el objeto del mismo no esté constreñido por urgencias de supervivencia. No podemos (debemos) discutir sobre bienestar mientras haya pobreza.

Nuestra posición, extrema como el patrimonio sobre el que trabajamos, ofrece una mirada pesimista; la de nuestro fracaso ante los retos que el patrimonio proponía. Una derrota que se explica por nuestra renuncia al papel de transmisión, incluso creación, de la idea de patrimonio cultural como herencia social y por tanto imprescindible como el aire que se respira.

Y dado que coincidimos con la consideración del patrimonio es una "construcción social", parece obvio-vemos los efectos- que no hemos tenido éxito en la mejora de su reconocimiento popular.
El patrimonio pertenece al pueblo, a la nación que se reconoce como tal. Y es por tanto tan diverso y amplio, tan cambiante, tan o tan poco relevante como desee el conjunto de la ciudadanía. Y será lícito discutir lo que queramos, pero más pronto que tarde debemos abrir ese debate al cerebro social, al generador de afectos, al valedor de las inversiones: debemos involucrar al pueblo mismo.

El concepto, el sentimiento resultante será la madera sobre la que labrar ahora debates más serenos sobre conceptos y metodologías, sobre lo que se desee. Y aunque desconocemos el resultado de ese análisis, tenemos por seguro que el esqueleto esencial de aquello que hemos delimitado los expertos seguirá siendo válido: muchas expresiones patrimoniales son estables, dignas del aprecio humano, de una admiración probablemente universal. Por ejemplo, entendemos que los matices de antigüedad serán respetados, como respetamos a nuestros abuelos, en general a nuestros predecesores.

En el fondo vemos este debate desde una perspectiva crítica, como si se tratara de un asunto no prioritario, como si tuviéramos otras necesidades en las que volcar nuestras energías. Por encima de todo -esperamos haberlo dejado claro a estas alturas- creemos necesario democratizar profundamente la gestión del patrimonio. Una idea que arranca en el mero acto de reconocimiento, y así nos llama la atención la escasa relevancia que han tenido los procedimientos de valoración patrimonial, discusión largamente abordada en otras geografías (por ejemplo, en LIPE, 1983).

A partir de ahí vendrán encadenadas todas las variadas acciones exigidas, en una estrategia que venimos describiendo como gestión integrada y que se refiere a la necesidad de abordar la preservación desde ambi- 


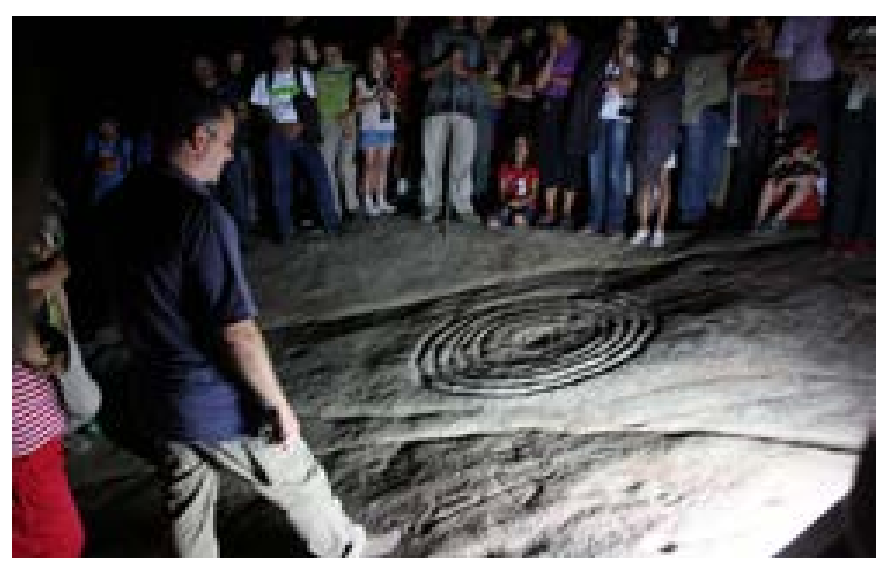

ciones amplias y en actuaciones múltiples y paralelas (CARRERA RAMíREZ, 2002). Se trata de esquemas de trabajo a muy largo plazo que no han resultado atractivos para la política, por lo que apenas se han implementado.

Y por encima de todo, dominándolo todo, deberá estimularse la participación de los diversos actores sociales en la definición de los objetivos y límites de las actuaciones. Y muy especialmente, priorizar la divulgación del sentido y oportunidad de las actuaciones en patrimonio, someterlas a la discusión pública. Un concepto por fortuna algo más de moda, la socialización del patrimonio.

Hay un espacio de acuerdo en el que debemos trabajar todas las disciplinas, con todas las fuerzas de las que seamos capaces. Una idea fuerza que permita construir en las sociedades su propio concepto de patrimonio, el que sea y con los desajustes que sean. Sólo a partir de ese aprecio podremos debatir junto con ellos los matices, los sutiles desacuerdos que renovarán nuestro pensamiento conjunto.

Los conservadores restauradores estamos dispuestos a ello. ¿Vienen con nosotros?

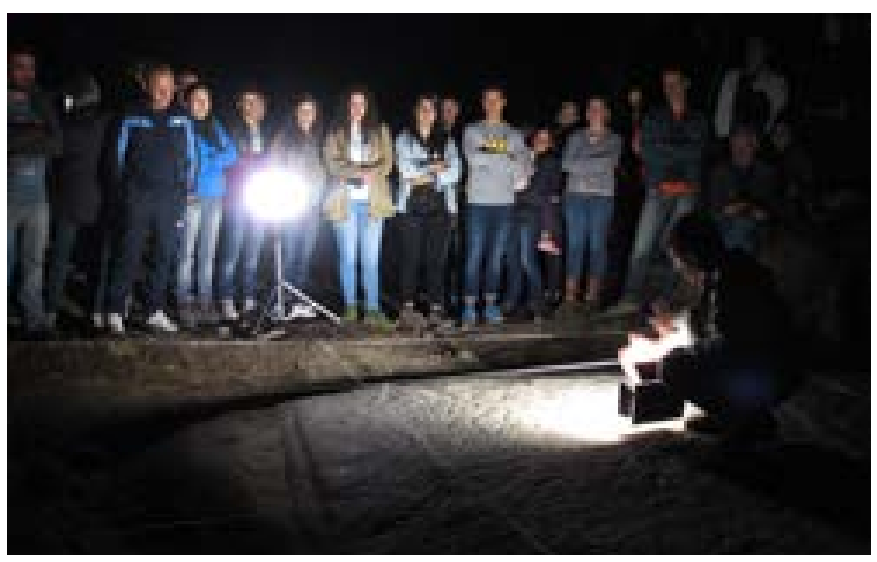

Visita guiada al finalizar una intervención en los grabados rupestres de "Pé de Mula" (Mondariz, Pontevedra) | fotos Fernando Carrera Ramírez

\section{NOTA}

1. Una opinión sobre este caso (y este debate) en CARRERA RAMÍREZ, F. (2016) El Patrimonio Cultural está hecho un eccehomo. Enmudecido (blog), miércoles 14 de septiembre de 2016 <http://enmudecido.blogspot. com.es/2016/09/el-patrimonio-cultural-esta-hecho-un. html>

\section{BIBLIOGRAFÍA}

- CARRERA RAMíREZ, F. (2002) La protección del arte prehistórico ibérico: ¿misión imposible? <http:// pendientedemigracion.ucm.es/info/arqueoweb/pdf/4-3/carrera. pdf> [Consulta: 07/03/2017]

- ARQUEOWEB: Revista sobre Arqueología en Internet, vol. 4, n. ${ }^{\circ}$ 3, 2002 <https://dialnet.unirioja.es/servlet/ articulo?codigo=1230913> [Consulta: 07/03/2017]

- LIPE, W. D. (1983) Value and Meaning in Cultural Resources. En CLEERE, H. (ed.) Approaches to the archaeological heritage. Cambridge: Cambridge University Press, 1983, pp. $1-11$ 